\title{
Reimagining Educational Experiences at a Critical Time
}

\author{
https://doi.org/10.3991/ijep.v10i3.12361 \\ David Guralnick $(\bowtie)$ \\ Kaleidoscope Learning \& International E-Learning Association \\ New York, New York, USA \\ dguralnick@kaleidolearning.com
}

As I write this from my apartment in New York, it's March 31, roughly 10 days into the "shelter in place" plan here. Over the course of my career, I've occasionally started writing something and then while I was partway done, something would change: an editor would suggest a different direction, a client's needs would change, that kind of thing. Never before have I begun writing an article and had the world change as I was midway through - until now. As I was partway through writing this piece, the COVID19 pandemic picked up speed dramatically, and while some of the points I initially planned to make still hold, others have changed.

I'd like to thank Matthias Utesch, Editor-in Chief of this journal, for the opportunity to participate in this very meaningful series, and to Matthias as well as Manuel Castro, Elio Sancristobal, and Thrasyvoulos Tsiatsos for their previous contributions to the series. The work of all of these people, both in the past and through the previous editorials in this series, has contributed tremendously to the field and certainly influences my thoughts below.

We're at a time of change in the world of education, and I see this is a time of great opportunity to use technology to help us not only improve people's access to education, but to alter and improve the educational methods we use in order to make our educational experiences more effective and more enjoyable.

If we take a look far back in time, education in the early days followed a different structure than we see today. For example, people used to learn via the apprenticeship model: if you wanted to learn, say, to be a blacksmith, you'd work with an experienced "master" blacksmith, you'd typically start with smaller tasks and work your way up, the master would coach you and provide feedback. Apprenticeships are a solid, effective educational model; they include learning by doing, coaching guidance, feedback, and gradual skill acquisition, among other valuable educational components. But apprenticeships don't scale up well! When society later needed to teach large numbers of people, there weren't enough experts, and the experts weren't necessarily located geographically near the potential apprentices. So the apprenticeship model survived but no longer flourished; overall, the classroom model took hold, out of necessity-one teacher, many students, the students did more listening and testing than doing. This was typically all that could be done given the constraints.

But with the technology we have today, many of those constraints have now been removed. We can create effective, immersive, interesting, enjoyable experiences online that do scale up to use by as many students as needed, anywhere in the world! These experiences can be designed to be used on their own or as part of a class with a professor or instructor who plays the role of expert facilitator, coach, and discussion leader rather 
than that of lecturer. This educational style allows people to learn more effectively and enjoyably, gives people more control over their learning experience, and, perhaps most important, helps people learn to make decisions and think critically, rather than to memorize and recite facts.

Instead of simply using technology to expand the reach of traditional lectures and testing, we can spend more effort and creativity to design new types of experiences. While my own experience is not specifically in engineering education, but in online learning more broadly for both workplaces and universities, some of the work I've seen in the engineering education world follows new models already.

Below are several technologies that are currently becoming more mainstream, along with my thoughts about ways that we can use them to reimagine educational experiences.

Virtual Reality (VR) and Holograms: We could create realistic learning-by-doing simulations and games for nearly any content area. Imagine learning about ancient Greece by exploring it in VR and then having a simulated conversation with Socrates, or for the workplace, becoming an expert salesperson by gaining realistic experience by practicing on virtual customers, with the help of a coaching component. In these examples, all learning is situated in context, which cognitive science research tells us greatly facilitates learning. And it also helps people enjoy the learning experience and, typically in my experience, feel as if the learning experience itself is respectful and supportive. The opportunities for skill-driven learning, the importance of which Matthias Utesch raised in the first editorial in this series, is tremendous. Experiences can facilitate critical thinking skills, a key point raised by Manuel Castro and Elio Sancristobal in their editorial, and involve game-like environments, a key component noted by Thrasyvoulos Tsiatsos in his editorial.

Augmented Reality (AR): AR experiences could, for example, help someone learn about a place that they're visiting. For example, imagine if I were visiting Paris, walking down a street, and could turn on a component that would point out interesting sites and even connect me with other people who wanted to discuss them, or maybe point me to which of my own friends had also been to a certain site in Paris and wanted to discuss it as I was there myself.

AI-driven Experiences: Imagine if the coaching component I mentioned in the VR section above were intelligent and personalized, and knew you, your interests, and your strengths and weaknesses. It could guide you to explore things that you might be likely to find interesting, and much more. There are indeed potential privacy issues with this type of system, but the potential benefits are significant as well.

Intelligent Analytics: One of the drivers of an AI-based experience is the usage data we can collect about people's interactions with the system. Again, there are potential privacy concerns to be addressed, but intelligent analytics can help improve the learner's experience and also, in the aggregate, help us improve the software-we can use the aggregate data to uncover points of confusion, or things that people don't like about an experience, or things that a particular subgroup of people do like, etc. The possibilities are endless and can greatly inform our future design! 
Internet of Things: The notion that "online learning" refers to learning via computer seems outdated to me already. Of course we also have tablets and phones, and VR headsets, but intelligent devices can play a key role as well.

These are just a few examples! Imagine education with experiences as the centerpiece, and collaboration with peers, expert coaching, advice, and feedback around that!

We're at a critical time in our field and in the world, and in my view, technology allows us the ability to move to new educational models that result in learning experiences that are more enjoyable, more effective, and help people learn to think critically and solve problems. I see the current time as an opportunity, for us to progress radically in the field of education in ways that help society as a whole, both in the short-term and far into the future.

Overall, to me, these difficult times can lead us to a time of inspiration. Let's make the most of it.

David Guralnick, Ph.D. New York, March 31, 2020

David Guralnick holds a Ph.D. from Northwestern University, where his work synthesized concepts from the fields of computer science and artificial intelligence, instructional design, and cognitive psychology. His work synthesizes concepts from several fields with the goal of using new technology to create immersive experiences that reimagine education and training. Over the past 30 years, he has designed and evaluated simulation-based training applications; performance-support systems, a variety of online courses for corporate, non-profit, and university audiences; mobile applications; and authoring tools.

David is president and CEO of New York-based Kaleidoscope Learning; president of the International E-Learning Association (IELA) and founding chair of the International E-Learning Awards program; an Adjunct Professor at Columbia University; a regular keynote speaker at international conferences; founder and chair of the International Conference on E-Learning in the Workplace (ICELW); Editor-in-Chief of the International Journal on Advanced Corporate Learning (iJAC); and was founding chair of the American Society for Training \& Development (ASTD)'s New York E-learning Special Interest Group; and a regular keynote speaker at both academic conferences and industry events. 